\title{
Photochemical effects of white light on the Briggs-Rauscher self-oscillatory reaction
}

\author{
(C) Andrey P. Rytik, * and Sergey Yu. Doronin ${ }^{+}$ \\ N.G. Saratov National Research State University Chernyshevsky. Astrakhanskaya St., 83. \\ Saratov,410012.Russia.Phone:+7 (8452)26-45-53.E-mail:Doroninsu@mail.ru
}

\begin{abstract}
*Supervising author; ${ }^{+}$Corresponding author
Keywords: self-oscillating processes, briggs-rauscher reaction, synchronization, "frequency pooling" effect, threshold effect, oscollation phase.
\end{abstract}

\section{Abstract}

For the Briggs-Rauscher reaction, the synchronization effect for concentration self-oscillations of the system components under exposure to external periodic white light was investigated. The high sensitivity of the self-oscillatory mode of the reaction to periodic exposure to the light is demonstrated. The sync band dependence on the light power has been revealed. The power limits of external light exposure for which selfoscillations are not going on, have been established. The maximal oscillation synchronization range under external light exposure (from 0.04 up to $0.10 \mathrm{~Hz}$ ) has been determined. "Frequency pulling" effect was observed for exposure to light with frequencies from 0.029 up to $0.039 \mathrm{~Hz}$ and from 0.10 up to $0.14 \mathrm{~Hz}$. Under the influence of light from a lamp with a power of more than $500 \mathrm{~W}$, the reaction was "turned off", which is probably due to an increase in the rate of formation of intermediate components of the system and an increase in their concentrations at which it exited from a state of self-oscillation to a stationary state. In addition, the periodic exposure to white light led to "adaptation" of concentration oscillations of the BR reaction to the external action into the phase that is characterized by the blue color of the solution (the formation of clathrate "iodine-starch"), which can be explained by a sharp decrease in the concentration of hydrogen peroxide in the system and, consequently, oxygen. The sensitivity of the Briggs-Rauscher reaction to the spectral composition of the initial source indicates the expediency of its further studies.

\section{References}

[1] J.A. Higgins. A chemical mechanism for oscillations in glicolitic intermediates in yeast cells. Proc. Nat. Acad. Sci. USA. 1954. Vol.51. No.6. P.989.

[2] Yu.I. Dytnersky, V.P. Brykov, G.G. Kagramanov. Membrane gas separation. Moscow: Chemistry. 1991. 344p. (russian)

[3] V.A. Vavilin. Autocatalysis and fluctuations in nature. Nature. 2005. No.6. P.52. (russian)

[4] V.V. Apari, S.G. Dmitrienko, Yu.A. Zolotov. Analytical capabilities of digital colorimetric technologies Moscow University Bulletin. Ser. 2. Chemistry. 2011. Vol.52. No.1. P.36. (russian)

[5] P. De Kepper, I.R. Epstein. Mechanistic study of oscillations and bistability in the Briggs-Rauscher reaction. Journal of the American Chemical Society. 1982. Vol.104. No.1. P.49.

[6] E. Dulos, P. De Kepper. Experimental study of synchronization phenomena under periodic light irradiation of a nonlinear chemical system. Biophysical chemistry. 1983. Vol.18. No.3. P.211.

[7] E. Kumpinsky, I.R. Epstein, P. De Kepper. Model study of synchronization and other phenomena in light perturbation of the Briggs-Rauscher reaction. International journal of chemical kinetics. 1985. Vol.17. No.3. P.345.

[8] Mkr. Reddy, Z. Szlavik. Influence of Light on the Inorganic Part of the Ruthenium-Catalyzed BelousovZhabotinsky Reaction. Journal of Physical Chemistry. 1995. Vol.99. No.41. P.15081.

[9] V.K. Vanag, A.M. Zhabotinsky and I.R. Epstein. Pattern Formation in the Belousov-Zhabotinsky Reaction with Photochemical Global Feedback. J. Phys. Chem. A. 2000. Vol.104. No.49. P.11566.

[10] R. Toth, A.F. Taylor. The tris (2,2 '-bipyridyl) ruthenium-catalysed Belousov-Zhabotinsky reaction. Progress in Reaction Kinetics and Mechanism. 2006. Vol.31. No.2. P.59.

[11] A.P. Rytik, D.A. Usanov. Effect of Electromagnetic Radiation on the Griggs-Rauscher self-oscillatory reaction. J. Physical chemistry. 2013. Vol.87. No.5. P.891. (russian)

[12] D.A. Usanov, A.V. Skripal, T.B. Usanova. Methods of investigation and correction of eye movement during nystagmus. Saratov: Publishing House Sarat. University. 2008. 116p. (russian)

[13] A.M. Zhabotinsky, H. Ogmer, R. Field, et al. Oscillations and traveling waves in chemical systems. Moscow: Mir. 1988. 720p. (russian) 